\title{
La gubernamentalidad neoliberal y la sustentabilidad en el planeamiento urbano: un análisis de las racionalidades del Modelo Territorial 2010-2060 para la ciudad de Buenos Aires
}

\footnotetext{
Margarita Gutman

Doctora en Arquitectura, Universidad de Buenos Aires (UBA). Profesora consulta y miembro de la Comisión de Doctorado, Facultad de Arquitectura, Diseño y Urbanismo (FADU, UBA). Full professor of Urban Studies and International Affairs y codirectora del Observatory on Latin America (OLA), The New School University, Nueva York.

gutmanm@newschool.edu

Ignacio Rullansky

Doctor en Ciencias Sociales, Universidad de Buenos Aires (UBA). Licenciado y profesor en Sociología, UBA. Magíster en International Affairs, The New School, y en Ciencia Política, IDAES, UNSAM. Becario doctoral del CONICET y estudiante dentro del doctorado en Ciencias Sociales, UBA. Miembro del CES, IDAES, UNSAM y coordinador del Departamento de Medio Oriente de la UNLP. Profesor en Universidad de Belgrano y en Universidad Torcuato Di Tella. Editor de la Revista Unidad Sociológica. irullansky@unsam.edu.ar
}

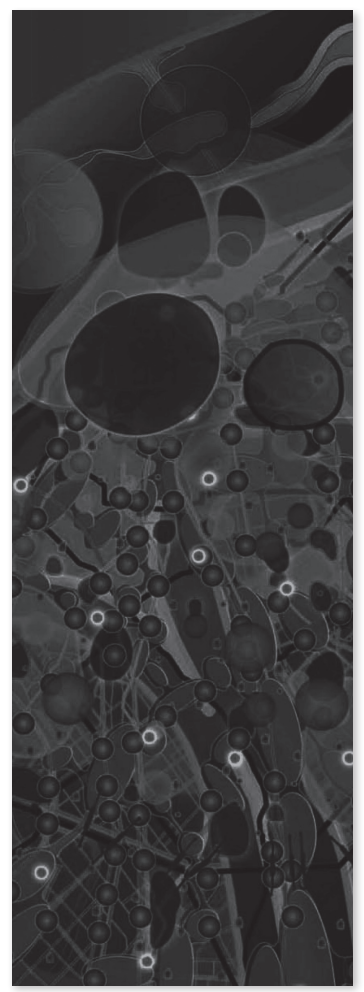


La gubernamentalidad neoliberal y la sustentabilidad en el planeamiento urbano: un análisis de las racionalidades del Modelo Territorial 2010-2060 para la ciudad de Buenos Aires

\section{Resumen}

En este artículo analizamos la articulación del discurso de la sustentabilidad y la racionalidad política neoliberal en el ámbito del planeamiento urbano. Nuestra indagación se centra en las racionalidades de las autoridades del gobierno de la Ciudad Autónoma de Buenos Aires de 2007 a 2015. En efecto, la Subsecretaría de Planeamiento, del Ministerio de Desarrollo Urbano, publicó en 2009 un documento que delineó los principios para el diseño de políticas públicas: el Modelo Territorial Buenos Aires 2010-2060. Aquí se plasmó una visión prospectiva para la ciudad que introdujo el discurso de la sustentabilidad como lógica transformadora, pues permitiría a las autoridades comprender las dinámicas tendenciales de la población y habilitaba la producción de tecnologías para conducir dichas prácticas. A partir de la técnica del análisis de contenido, estudiamos cómo las máximas autoridades de gobierno rubricaron en este documento una vocación de gobernar eficazmente la relación entre sociedad, economía y medio ambiente.

\section{Palabras clave}

Gubernamentalidad; planeamiento urbano; sustentabilidad; Buenos Aires.

\author{
Neoliberal governmentality \\ and sustainability in urban \\ planning: an analysis \\ of the rationalities of the \\ Territorial Model 2010-2060 \\ for the city of Buenos Aires
}

\section{Abstract}

In this article we analyze the articulation of the discourse of sustainability and neoliberal political rationality in the field of urban planning. Our research focuses on the rationalities of the authorities of the government of the Autonomous City of Buenos Aires from 2007 to 2015. Precisely, the Undersecretary of Planning, of the Ministry of Urban Development, published in 2009 a document that outlined the principles for the design of public policies: the Buenos Aires Territorial Model 2010-2060. In this document, a prospective vision for the city was embodied, presenting the sustainability discourse as a transformative logic, since it would allow the authorities to understand the dynamic trends of the population, enabling the production of technologies to conduct such practices. Using the content analysis technique, we study how the highest government authorities established in this document, a vocation to effectively govern the relationship between society, economy and environment.

\section{Governamentalidade neoliberal e sustentabilidade no planejamento urbano: uma análise das racionalidades do Modelo Territorial 2010-2060 para a cidade de Buenos Aires}

\section{Resumo}

Neste artigo, analisamos a articulação do discurso da sustentabilidade e da racionalidade política neoliberal no campo do planejamento urbano. Nossa investigação se concentra nas racionalidades das autoridades governamentais da Cidade Autônoma de Buenos Aires de 2007 a 2015. De fato, a Subsecretaria de Planejamento, do Ministério do Desenvolvimento Urbano, publicou em 2009 um documento que traçava os princípios para o desenho de políticas públicas: o Modelo Territorial de Buenos Aires 20102060. Aqui foi capturada uma visão prospectiva para a cidade que introduziu o discurso da sustentabilidade como uma lógica transformadora, pois permitiria às autoridades compreender as dinâmicas das tendências da população e possibilitar a produção de tecnologias para conduzir tais práticas. Utilizando a técnica de análise de conteúdo, estudamos como as mais altas autoridades governamentais firmaram neste documento uma vocação para governar efetivamente as relações entre a sociedade, a economia e o meio ambiente.

\section{Key words}

Governmentality; urban planning; sustainability; Buenos Aires.

\section{Palavras chave}

Governamentalidade; planejamento urbano; sustentabilidade. 


\section{Introducción}

Desde diciembre de 2007 a diciembre de 2015, Mauricio Macri, líder de la alianza Propuesta Republicana (PRO), gobernó la Ciudad Autónoma de Buenos Aires. Durante su gestión, la Subsecretaría de Planeamiento, organismo perteneciente al Ministerio de Desarrollo Urbano, publicó en 2009 un documento que delineó los principios orientativos para el diseño de políticas públicas: el Modelo Territorial Buenos Aires 2010-2060 (en adelante, MT). En sus páginas se plasmó una visión prospectiva para la ciudad que introdujo el discurso de la sustentabilidad como lógica transformadora.

Entre los autores del texto figuran no solo el propio Macri, su ministro de Desarrollo Urbano, Daniel Chaín, y el entonces subsecretario de Planeamiento Héctor Lostri, sino que se alude a un equipo interdisciplinario de asesores e investigadores. En conjunto, quienes participaron de la confección del MT implementaron un relevamiento sobre distintos aspectos de la realidad social, económica y ambiental, ofreciendo un diagnóstico acerca del estado de la ciudad, sus industrias, los modos de circulación, su infraestructura urbana y espacios verdes. En síntesis, el documento resume el resultado de procesos que incluyeron discusiones legislativas y las entabladas entre arquitectos, urbanistas y autoridades políticas respecto de los relevamientos y propuestas, así como consultas a expertos e instancias de participación de la ciudadanía.

A efectos de comprender las dinámicas tendenciales de la población, el MT no solo establece una instantánea sobre el presente de su elaboración, sino que pauta una metodología para abordar el análisis de las conductas estudiadas. Su objeto explícito es habilitar la producción de tecnologías para el gobierno de los usos de modos de transporte y prácticas de circulación, cercanía y acceso a centralidades comerciales y productivas y a espacios verdes. Dichas tecnologías apuntan a la "humanización" del espacio urbano para facilitar una cierta conducción de las prácticas (cotidianas, laborales, de circulación) de la población, acercándolas a un ideal de eficientización. Veremos más adelante cuál es la especificidad de la acepción que asumen estos términos, pero podemos adelantar que dicha idea de "eficacia", tal como fue presentada por las autoridades en el MT, propugnó gestar escenarios capaces de evitar crisis económicas y sociales. Todo esto parte de una concepción sistémica del orden social, que presenta la articulación entre economía, sociedad y medio ambiente como elementos interrelacionados, susceptibles de cuantificarse en índices. Dichos instrumentos de 
observación devendrían, acorde con el MT, indispensables para propugnar una articulación eficiente entre sus respectivos aspectos. El discurso que se implementa para dotar de sentido a esta noción es tempranamente comentado: el de la sustentabilidad.

Precisamente, el MT es introducido por tres discursos firmados, correspondientemente, por las autoridades oficiales mencionadas: Macri, Chaín y Lostri. Cada uno de ellos, sostendremos, presenta un elemento que compone un campo discursivo mayor: una racionalidad política específica acerca de cómo ejercer el poder de gobierno en la Ciudad de Buenos Aires, en lo referente a la articulación de prácticas de gobierno y de las conductas de la población. Precisamente, el planeamiento urbano devino, en el MT, el campo donde la evaluación de la realidad social y la concepción de los medios para su rectificación se manifiestan posibles: son las políticas urbanas aquellas que promoverán —conforme la racionalidad política manifiesta en el texto- transformaciones sustantivas de cara a mejorar el balance entre economía, sociedad y medio ambiente. Se trata, pues, de la incorporación de una acepción particular del discurso de la sustentabilidad que, como veremos, se halla íntimamente vinculada con la racionalidad política neoliberal típicamente identificada con la gubernamentalidad neoliberal.

Debemos destacar que Jajaмоvich (2012) ofreció un análisis sobre el MT en el que, crítica e integralmente, examina la propiedad metodológica del documento y su presunta eficiencia a partir de la introducción de un conjunto de indicadores subsumidos en el Índice de Sustentabilidad Urbana (ISU). Asimismo - y compartiendo la observación de JajAMovich (2012)—, Espina, Foray, LERENA Rongvaux y Moroni (2013) se ocuparon de señalar la dificultad de proyectar un equilibrio más igualitario entre las dimensiones económica y social que aborda el MT: el enfoque, eminentemente conservador, del documento no propugna más que repensar las condiciones para tornar eficaz y, por tanto, sostenible en el tiempo, un modo de acumulación. Ambos aportes son indudablemente significativos para contemplar cómo el discurso sustentable es incorporado en la generación del ISU y cómo las nociones de crisis y conflicto fueron tematizadas. En esta oportunidad, intentaremos expandir el estado de la cuestión explorando, específicamente, qué es lo que las autoridades responsables de la elaboración y publicación del MT oportunamente entendieron por sustentabilidad. En efecto, nos interesa comprender cómo se configuró discursivamente la cuestión social a partir de la acepción de sustentabilidad comentada, cuya definición teórica pasaremos a operacionalizar, luego de reseñar los conceptos de gubernamentalidad neoliberal y racionalidades políticas. 


\section{La gubernamentalidad neoliberal}

Comenzaremos presentando algunas nociones centrales, entre ellas, el término "gubernamentalidad". Acuñado por Michel Foucault (1991), designa una concepción de los esfuerzos del poder político de poseer un conocimiento sobre aquello que constituye el objeto de su gobierno. Por gubernamentalidad se entiende la preeminencia de una "mentalidad" — una reflexión sobre qué medios disponer y cómo- para gobernar — sobre un ámbito y objeto específicos-y hacer operable su ejercicio sobre otras formas de poder político.

En esta corriente teórica, las racionalidades políticas entrañan una serie de reglas, formas de pensar, procedimientos tácticos, a partir de las cuales un actor, en tanto "autoridad política", concibe alguna cuestión como un "problema", para generar alternativas para su resolución (Rose \& Miller, 1992). Las racionalidades políticas pueden expresarse como campos discursivos de configuración cambiante, en cuyo marco se produce una conceptualización del ejercicio del poder que incluye justificaciones acerca de los modos particulares de dicho ejercicio por parte de los diferentes tipos de autoridades: sean estatales o no estatales. Estas encaran la cuestión de quién puede gobernar, qué es gobernar, qué o quién es gobernado: en nuestro caso, estudiaremos cómo las autoridades del gobierno de la ciudad de Buenos Aires en el período establecido instauraron prácticas discursivas abocadas a la tematización de un compendio de problemas en el ámbito del planeamiento urbano.

En esta línea, Brown (2015) sostiene, junto con Foucault, que el neoliberalismo puede ser entendido como un orden normativo de razón que asume la forma de una racionalidad política: una que extiende la formulación específica de valores, prácticas y métricas económicas en cada dimensión de la vida humana, "economizando" a partir de su diseminación, los procesos de constitución de subjetividades. Dos conceptos convergen en este intersticio: las "tecnologías del yo" y el "cuidado de sí", que designan la configuración de un sujeto caracterizado por realizar un "auto-conocimiento" de sí. En otras palabras, sujetos que ofician una ponderación de sus "libertades", y actúan "como si fueran" calculadores racionales de beneficios y costos de oportunidad en la vida cotidiana (Brown, 2015; Dilts, 2011; LemKE, 2001; Rose \& Miller, 1992). En su trayectoria laboral, el sujeto capitaliza habilidades personales en tanto "emprendedor"; responsable de su propio bienestar, es asimismo un activo valorizado en el mercado como un "capital humano", capaz de asumir el riesgo social que otrora afrontaba el Estado, renunciando así, inclusive, a derechos conquistados en luchas previas (Dilts, 2011; LeMKE, 2001). 
Según BRown (2015), las democracias contemporáneas son atravesadas por un proceso de transposición semántica en lo referente a los principios de justicia, inclusión, equidad, libertad, propios de la política, para asumir rasgos económicos. Dado que en la praxis no es dable rastrear un mismo modo en que esto ocurre para todo tiempo y lugar (Brown, 2015), puede hablarse de "neoliberalismo realmente existente" (Theodore, Peck y Brenner, 2009) para referirse a la multiplicidad de casos en los que se aprecia la expansión de dicha racionalidad. Los rasgos señalados localizan al sujeto del neoliberalismo como un ciudadano que se comporta como una empresa: cual agente económico. La noción de neoliberalismo realmente existente permite aprehender cómo tiene lugar la adopción de prácticas discursivas y extra-discursivas consistentes con este tipo de gobierno.

A lo largo de nuestra investigación relevamos documentos de planeamiento urbano publicados por agencias gubernamentales, centrándonos eminentemente en el MT, pues asume una centralidad ineludible para el estudio del desembarco del neoliberalismo -observado como expresión sociohistórica, realmente existente- en la esfera de gobierno de la capital federal de la Argentina. Nuestro objetivo consistió en identificar y comprender las racionalidades políticas expresadas en las páginas del MT en torno a la cuestión social y la marginalidad: nos propusimos entender cómo las autoridades políticas oficiales confeccionaron una metodología de relevamiento y evaluación de la realidad social que sería adoptada como principio de planificación en otros documentos de subsiguiente publicación. Para ello, implementamos la técnica del análisis de contenido a partir del estudio de enunciados, rescatando su flexibilidad metodológica para considerar teoría existente y la especificidad contextual de los discursos estudiados (Neuendorf, 2002; Hsien y Shannon, 2005). El diálogo entre teoría y datos que propone esta técnica permite reexaminar, corregir y afianzar preguntas-problema. Desde este marco teórico, implementamos un esquema de codificación intuitivo, abierto a explorar el carácter relacional entre teoría y datos (Neuendorf, 2002), indagando en la relación entre sustentabilidad y neoliberalismo presente en los discursos de las autoridades políticas aludidas.

Como expondremos a continuación, pese a que algunos de estos planes expresen la vocación de sus autores por atender la cuestión social, en general, se aprecia la formulación de una noción sistémica sobre las conductas de la población de la ciudad a partir de una acepción particular del concepto de "sustentabilidad". Dicho criterio "sustentable" propende a la cuantificación de prácticas y refleja el interés de las autoridades oficiales de conocer, 
para gobernar variables medibles. Segundo, este conocimiento es empleado en términos normativos: el saber técnico ofrece las claves de desentrañamiento de problemáticas que pueden identificarse como tales y tematizarse según sus dinámicas tiendan a escenarios prospectivos de crisis o equilibrio. Tercero, entendemos que la interrelación entre variables marcadas en estos documentos constituye al ciudadano como unidad mínima en tanto sujeto político y objeto de las políticas que diseñar, según la predictibilidad de conductas.

En otras palabras, se presenta al sujeto como uno cuyas prácticas pueden anticiparse desde este conocimiento técnico, y que pueden modularse gracias a la intervención estatal. La traducción de racionalidades políticas a tecnologías de gobierno capaces de consagrar dicha modulación es observable en la confección de estos planes, que presentan un sujeto consistente con la caracterización hecha anteriormente: actúa "como si fuera" un agente sensible a variables que pondera según un criterio económico. La dirección de esta conducta en términos de "equilibrio", expresada en los documentos, es lo que permite cifrar la presentación del criterio sustentable aquí incorporado, como una posible acepción neoliberal del término.

\section{La relación entre la gubernamentalidad neoliberal y la sustentabilidad}

En líneas generales, la sustentabilidad implica una acción de respuesta a circunstancias extremas implementada bajo la modalidad de una transformación: opera como sostén del bienestar humano y del funcionamiento del sistema ante problemas ambientales y ecológicos severos (Redman, 2014; Leach, Stirling \& Scoones, 2010). La sustentabilidad imprime una estrategia tendiente a la reconfiguración de los elementos que componen un sistema a partir de nuevas dinámicas relacionales que provean valores deseables a largo plazo. En síntesis, el sistema "debe reorientar" sus funciones y elementos para sobrevivir: se genera un orden diferente del statu quo conocido. La adopción de un discurso sustentable traducido a la esfera de gobierno implica la asunción de riesgos a futuro al diseñar y desplegar estrategias transformativas.

Como apuesta al futuro, la reconfiguración "sustentable" de un sistema debe garantizar el bienestar humano, la equidad social y la integridad ecológica/ambiental para las generaciones venideras (REDMAN, 2014; LEACH ET AL., 2010). Esta orientación es habitualmente concebida como un "pasaje" o "tránsito" hacia algo distinto. Sobre este punto se tienden los puentes 
entre los campos político (planificación, policy-making, ejecución) y científico (agentes expertos): los primeros se apoyan en el discurso de los segundos (presumiblemente neutral, confiable) para legitimar prácticas de gobierno (GIBSON, 2006; LEACH ET AL., 2010; SMITH \& Stirling, 2010; Bettencourt \& Kaur, 2011).

Una crítica frecuente al "desarrollo sustentable” consiste en señalar que este formula "sustentabilidades justas” integrando prioridades ambientales y económicas, mas no propone cambios en las estructuras que reproducen la inequidad y exclusión social. En el MT se observa que prevalece en la relación "sustentable” el peso de variables ambientales y económicas sobre las sociales y políticas. Entre otras limitaciones, se destaca en dicho documento la fragmentación de la proyección de paisajes conflictivos que colisionan entre sí con escasas posibilidades de alcanzar una práctica exitosa debido a múltiples y contradictorias encarnaciones de la noción de sustentabilidad, codificada eminentemente en términos neoliberales (CENTNER, 2009).

Por su parte, Riechmann (1995; 2003) señala aspectos positivos del desarrollo sustentable, apuntando a la liberación del espacio ambiental y la "minimización del daño" a la biosfera, con el fin de consagrar justicia intergeneracional. Sin embargo, el autor también reconoce las dificultades respecto de la consolidación de transformaciones "sustentables”, dado que la persistencia de la desigualdad social y de múltiples formas de opresión no es contradictoria con políticas presentadas como “eco-eficientes” (Riechmann, 2005).

En tal sentido, LEMKE (2002) da cuenta del proceso de conversión en un activo económico de aquellos aspectos de la naturaleza y de la sociedad, que genera una capitalización según el valor comercial que adquiere "la biosfera" a partir la intervención de la biogenética. Un ejemplo de ello es la industria farmacéutica y la explotación de recursos naturales en selvas tropicales, como el Amazonas (Lemke, 2002). Precisamente, el contexto de emergencia de la noción de sustentabilidad coincide con el del neoliberalismo, entendido como una ideología de organización económica que presume que la optimización de la vida puede granjearse a partir de la coordinación de paradigmas coordinados a través del mercado, de modo tal que el Estado se restringe a actuar como un operador de su encumbramiento y optimización (Veltmeyer, Petras \& Vieux, 1997; Mohan, Brown, Zack-Williams \& Milward, 2000; Babb, 2005; CEnTNER, 2009). En ese contexto histórico, las principales capacidades y conceptos clave de la sustentabilidad se traducen en la formulación de programas de gobierno concretos (RosE 
y Miller, 1992; Gordon, 1991), como es el caso de los modelos, planes urbanísticos y leyes. Entre los elementos prioritarios mencionados en los discursos del desarrollo sustentable y que se explicitan en el MT, figuran la sustentabilidad, la participación y la competitividad como conceptos básicos para respetar. Aquí nos preguntamos por la tematización de la cuestión social en esta episteme y metodología, tendientes a estimular escenarios que apuntan al orden, a la armonía entre clases, pero sin desmantelar las desigualdades estructurales presentes en el momento de su elaboración.

\section{La racionalidad neoliberal y la sustentabilidad en el MT}

El cuerpo del texto comienza evidenciando tres grandes dimensiones del discurso sustentable: 1) legitimidad y justificación de este enfoque como clave de desarrollo para la administración pública y presentación de la ciudad sustentable como principio de orientación para Buenos Aires; 2) especificidad histórica del MT: documento introductorio de la sustentabilidad como eje de la planificación para la ciudad; 3) la metodología, herramienta de la sustentabilidad y la asociación entre riesgo-velocidad y la proyección a futuro como ejercicio de adaptación sistémico.

A continuación, analizaremos dimensiones de los discursos rubricados al comienzo del documento por los mencionados actuantes jefe de Gobierno, ministro de Desarrollo Urbano y subsecretario de Planeamiento: respectivamente, Mauricio Macri, Daniel Chaín y Héctor Lostri. Entendemos que estos textos manifiestan dimensiones de una racionalidad política, verbalizada por cada funcionario según un criterio temático. El primero presenta el enfoque y explica por qué seguirlo, mientras que otro expone cómo opera este enfoque cual bisagra entre pasado, presente y futuro, es decir, dotando de especificidad histórica a su temporalidad, para que el último indique los elementos metodológicos y técnicos que presumiblemente convalidan su adopción.

En primer lugar, la intervención de Macri enuncia que detrás del proceso de planeamiento urbano, y en especial, de producción del MT, existen discusiones políticas sobre las que no se ahondará: en el texto parecieran resolverse cuestiones dirimidas puertas adentro, manifiestas solo para el ámbito de la planificación. Asimismo, esta intervención introduce la noción de ciudad sustentable como principio de desarrollo para Buenos Aires, indicando la relación directa entre la voluntad de implementar políticas públicas y la prospección 
de una mejoría de la calidad de vida. Lejos de constituir algo novedoso, sí es sustantivo el registro discursivo en la clave de la sustentabilidad: la alusión a la ciudad "proyectada", aspiración en la que presumiblemente se gozará de mejores condiciones de vida, es una ciudad eminente e invariablemente sustentable.

Esa proyección sustentable representa la realización de una idealidad: un horizonte de sentido para la administración pública. El modo de encarar ese futuro supone una continuidad en la línea de trabajo propuesta por el MT, que trasciende a la gestión. Más adelante en el MT, se presenta una secuenciación de fases de ciudades "tendencial" y "deseada" como escalones hacia una sustentable. Esto ilustra que el gobierno que ofició de actor dilucidador de una realidad contemporánea proveyó el diagnóstico y los criterios que seguir para la resolución de las problemáticas plasmadas en el documento, asumiéndose como uno más de una sucesión que trabajaría en torno a semejante agenda sustentable. Una primera mención a las dimensiones clásicas de la sustentabilidad ilustra esto: "Partimos de algunas definiciones que dan sustento a nuestra tarea y del deseo de hacer de Buenos Aires una ciudad más justa, más inclusiva, más competitiva y más humana" (MACRI, CHAin y Lostri, 2009, p. 6). Esta cita se retrotrae a las nociones y ejes comúnmente aceptados sobre la noción de sustentabilidad, antes reseñadas. En efecto, un rasgo discernible que no resulta desatinado ni particularmente objetable es que para establecer definiciones y criterios, los autores del MT hayan extraído elementos del estado del arte de la sustentabilidad. Forma parte de la edificación de esta racionalidad política una imbricación entre vocaciones y saberes técnicos, académicos y gubernamentales:

El Modelo Territorial se constituye, por todo esto, en una política de Estado que supera ampliamente los períodos en los que se desarrolla una administración. Sostenemos que la sustentabilidad de la Ciudad también tiene que ver con esto, con poder superar los tiempos que impone la política para establecer un debate a largo plazo, que se vea enriquecido con los aportes y transformaciones de la realidad porteña presente y futura. En la actualidad, es imposible separar la idea del mejoramiento hacia el mañana del logro de objetivos referidos al ambiente de Buenos Aires. El ambiente es una construcción social que implica la relación entre las personas y su entorno y, por lo tanto, muestra el resultado de la intervención humana sobre la naturaleza. En particular, el ambiente urbano muestra los resultados de la transformación más extrema y, con relación a esto, presenta asimismo los efectos indeseados de estas modificaciones realizadas sobre el paisaje natural (MACRI ET AL., 2009, p. 6). 
En esta relación, lo ecológico probará ser la dimensión que los funcionarios y los metodólogos que diseñan el resto del documento tomarán como principal. En torno a ella, se articula la dimensión económica, que vendrá en segundo lugar de importancia, y luego la social, más relacionada con la calidad de vida en materia de afectación ambiental y de integración en sistemas económicos, que de cuestiones vinculadas con la desigualdad material. El ejercicio de la gubernamentalidad que se desprende del despliegue de la orientación propuesta en el MT constituye uno de adaptación sistémica a nuevas condiciones, suponiendo un reordenamiento "eficiente" de las relaciones entre sus elementos.

En términos sociológicos, se asume que dicho reordenamiento implica una operación que posibilita contrarrestar situaciones de anomia, manifestadas a partir de grandes crisis económicas, como las de 1930 y 2001-2002, harto citadas y reseñadas como panoramas que evitar por sus consecuencias perniciosas sobre la estabilidad política y social. Ahora bien, el desplazamiento del eje de lo social a lo ecológico permite vadear la cuestión social, es decir, la pobreza, la marginalidad, abordándola solo desde la mejoría en términos de tipos de ciudad "saludable" y "plural", a la vez que se insiste en aumentar la presencia y diversidad de actividades económicas y mejorar su integración en cadenas de valor, a lo largo de la ciudad.

Esto significa que puede evitarse una anomia si la economía se halla lo suficientemente integrada (complejidad-diversidad) para responder a escenarios que sacudan sus industrias y, así, conmuevan los fundamentos de legitimidad de la representación política a partir del malestar y descontento social suscitado por la crisis. Asimismo, se especifica cómo se compuso el campo de intervención en aras de encaminarse hacia la sustentabilidad, destacándose la relación socio-ambiental como principio de regulación sistémica: "El grado de contaminación de las aguas, la disposición de los residuos sólidos urbanos, la congestión del tránsito y el excesivo consumo de energía son problemáticas que deben enfrentarse para asegurar el desarrollo urbano deseable en el futuro" (MACRI ET AL., 2009, p. 6).

En vez de encarar situaciones de vulnerabilidad y marginalidad directamente, este discurso supone que la eficiencia de la sustentabilidad en la gestión de los asuntos ecológicos y económicos reproducirá el orden que preservar: se trata de un discurso conservador. Las problemáticas ambientales, frecuentemente asociadas a la marginalidad y situaciones de vulnerabilidad localizadas en áreas concretas de la ciudad, no están ni manifiesta ni 
implícitamente relacionadas entre sí. El "gran desafío" que se propone, de tipo ambiental, parece aislarse del contexto social de su surgimiento y de las problemáticas que suscita. En cuanto a la construcción de los indicadores, se establece que responden a la misión prospectiva de planear una ciudad sustentable, considerándolos como instrumentos directos de los criterios que enmarcan la concepción de las políticas públicas que se implementarán: "La construcción de los indicadores que se utilizan en este Modelo tiene el espíritu de analizar para saber qué y dónde intervenir, qué camino hacia el futuro se puede emprender para dirigir mejor nuestros pasos" (MACRI ET AL., 2009, p. 6).

Además, el texto destaca el papel "activo" de los policy makers: si los indicadores operan como claves de desciframiento de dónde debe operarse para mejorar la ciudad como condición de posibilidad de mejorar las condiciones de vida, las autoridades oficiales serán no solo sus intérpretes, sino quienes ejecuten proyectos que atiendan a las características relevadas sobre las relaciones socio-espaciales. En torno a la prioridad que supone implementar una "humanización del espacio público", se responde:

¿Por qué humanizar el espacio público? ¿Qué significa esta "humanización”? La ciudad en su conjunto es un sitio de entrecruzamientos de relaciones de diverso tipo: sociales, personales, tecnológicas, laborales, comerciales y comunicacionales. Todas las personas, las organizaciones, los grupos sociales, existen influyéndose, condicionándose y modificándose mutua y constantemente; creando nuevas relaciones, en una espiral sin fin. En la ciudad, todo es comunicación. Y el espacio público es fundamentalmente un lugar de encuentro, por eso se constituye en un lugar estratégico para la intervención pública orientada a mejorar estos encuentros (MAcri ET AL., 2009, p. 6).

Las autoridades políticas presentan aquí su responsabilidad de asemejar el espacio físico de la ciudad a los términos ideales que habilitan el goce de los ciudadanos en ella. La vida grata es presentada como una en la que estos potencian sus cualidades a un nivel semejante al de la vita activa según ARENDT (2014), solo que en un esquema de libertad negativa o "moderna", a la manera que explicó Constant. La humanización del espacio público señalada como objetivo del diseño de políticas públicas implica una cierta asimilación del espacio a las expectativas y deseos de sus habitantes. En otras palabras, esto significa que el Estado entiende asumir la tarea de intérprete de las necesidades de la población, un rasgo que presumiblemente confiere legitimidad a la vocación de gobernar. 
Siguiendo a ARENDT, y a lo que Constant denomina como "libertad positiva o de los antiguos", el ejercicio colectivo y directo de la soberanía es compatible con la sujeción completa del individuo a la autoridad de la multitud reunida. Este último factor constituye la condición de la política para ARENDT: la multitud reunida, exenta de ocuparse del trabajo, se enfoca en lo más alto de la vita activa, la acción/praxis y discurso/lexis, entre otros. Se parte aquí de la noción de que, en la polis, solo se es libre entre iguales, donde cada uno manifiesta su propia unicidad, su particularidad, públicamente con sus pares (no se es libre, pues, en el hogar, en la esfera privada y oculta, donde se convive con personas carentes de virtudes y razón, como los niños, las mujeres y los esclavos).

La potenciación del goce y el cuidado de sí en un esquema neoliberal como el que representa esta acepción del discurso de la sustentabilidad evocan la condición de la vita activa, que es poder enfocarse en las tareas que hacen de un miembro de la polis, un ciudadano. El ejercicio de la vita activa, sin embargo, está restringido para una multiplicidad de sectores que son pasados por alto. Asoma aquí la primacía de la noción de homo economicus del neoliberalismo (BRown, 2015; LEMKE, 2002), cuya subjetividad se aboca al cálculo del costo y beneficio de actividades, responsable a su vez de su propio bienestar. En otras palabras, dicho homo economicus enmarca la noción de ciudadanía explicitada en el discurso analizado: una en que la desigualdad material es reconocida y en que el ejercicio de la libertad ciudadana consiste en potenciar las cualidades del capital humano que cotiza en el mercado.

Desde una perspectiva gubernamental, el ejercicio de gobierno de este homo economicus, de esta "máquina de habilidades", es de "correlación": habrán de conocerse y diseñarse las prácticas y técnicas más eficientes para desarrollar prudentemente sus habilidades, mantenerlas, ajustarlas, en suma, conducir las conductas de sujetos absortos en prácticas auto-interesadas (Brockling, 2011; Dilts, 2011). Para Foucault (2012), la explicación neoliberal de capital humano abre el terreno a la subjetividad. Por un lado, se realiza un corrimiento de la noción de poder de la soberanía (el sujeto como objeto de saber/poder en una red de relaciones de fuerza) para aprehender el rol que juegan los sujetos en su propia formación.

Si la libertad es una elección, las prácticas desplegadas por los sujetos se apreciarán según su retorno: la eticidad de la gubernamentalidad neoliberal radica en que las prácticas en 
general sean asumidas como prácticas de libertad, pues si los actores son racionales porque son sensibles, se sacrifica la posibilidad de ser críticos; el encuentro con otros queda sesgado por la primacía del auto-interés individual (BrockLing, 2011). Aquí, el regreso del "como si fueran" hace a los regímenes de verdad en que se constituye el sujeto del neoliberalismo, que asume una forma aparentemente universal porque el capital humano puede extenderse a cualquier persona y a sus decisiones sobre sus actividades (Dilts, 2011). Asimismo, este sujeto es gobernable porque actúa libremente y por necesidad de supervivencia: la estructura de incentivos necesarios para elegir libremente según cálculos requiere un gobierno (BRocKLING, 2011).

Todo esto sugiere que en citas como las anteriores la racionalidad política no se refiere a la red de relaciones de fuerza entre actores, es decir, a la desigualdad. Aquí, la cualidad ciudadana se circunscribe a un individuo libre que puede mejorarse por sí mismo, y el Estado solo procura brindar las condiciones ideales para ello. Consiguientemente, puede conectarse el discurso de la sustentabilidad con un arte de gobierno típicamente neoliberal a la manera de Rose y MILLER (1992) y GoRDon (1991). En definitiva, se trata de una racionalidad que apunta a un tipo de orden social regido a partir del despliegue de la gobernanza y mejores prácticas que caracterizan, según FoucAult (2012), LeMKE (2007) y BRown (2015), entre otros, el neoliberalismo.

La responsabilización, transferencia del Estado al individuo-ciudadano-emprendedor de velar por su propio bienestar, es un rasgo propio del desplazamiento de formas clásicas del Estado liberal y de bienestar. Mientras el ejercicio de gubernamentalidad provee los medios para que esta suerte de autonomización ocurra, bajo la presunción del comportamiento del ciudadano como homo economicus en cada vez mayores ámbitos de vida, se vacía el espacio público de contenido eminentemente político y, por ello, la cuestión social deja de resultar un eje abordado directamente para resolverse por efecto del mercado. En cierto sentido, parte de la población, conforme las implicancias de esta "responsabilización”, se volvería prospectivamente desechable (Brown, 2015). Por otro lado, cabe destacar una operación de antropologización del espacio, presentada como clave de potenciación del ciudadano:

En este sentido, recuperar la alegría y la convivencia entre vecinos y su disfrute del espacio de todos es una tarea imprescindible. De la importancia que tiene este espacio como soporte de la cultura urbana, entonces, es que nos planteamos la tarea de "humanizarlo". La humanización consiste, en definitiva, en dotar al espacio público de equipamiento e infraestructura para que 
sea disfrutable. El objetivo es brindar las condiciones para que el desarrollo de la vida urbana sea grata, para que en ella se desplieguen los valores y potencialidades de las personas. Nos inspira un profundo respeto y confianza en las capacidades humanas, y por eso nos proponemos trabajar por lograr el mejor espacio urbano posible (MACRI ET AL., 2009, p. 7).

La ciudad se alza como actriz protagonista de los procesos de desarrollo socioeconómico, y cual resultado de un proceso teleológico: allí se halla la vida, por eso dicho espacio debe humanizarse. Nuevamente, surge la dimensión del orden y, así, las de las relaciones de poder, esta vez, entre las ciudades con rasgos semejantes (metrópolis cosmopolitas/ciudades mercancía) a un nivel regional/internacional. Antes de eso, debe señalarse que la noción de humanidad en cuestión está íntimamente vinculada con la de capital humano, que adquiere su máximo potencial de realización y, de esa forma, transfiere su valor a la ciudad; es decir, el ciudadano-emprendedor constituye un activo en la puesta en valor de la ciudad y en el aumento de su competitividad respecto de otras.

La humanización del espacio público implica que el sentido primordial de la actividad civil, en este espacio, esté eminentemente imbuida por valores y sentidos económicos en sustitución —o al menos desplazando- de aquellas actividades deliberativas, de discusión, de resistencia, que hacen a la praxis de actores sociales en tanto sujetos políticos. Tal trasposición de significados que presenta la cualidad "humana" de la transformación del espacio público en cuestión, siguiendo a Brown (2015), es distintiva del neoliberalismo y del vaciamiento de elementos característicos de las democracias liberales clásicas. Veamos cómo sigue el texto respecto de otra cuestión:

Estas ciudades son, actualmente, las metrópolis líderes en cuanto a localización de actividades económicas, generación de riqueza y también — situación que se relaciona directamente con estas características-, concentración de la población. A principios del nuevo milenio, estas metrópolis devienen en actores protagonistas de los procesos de desarrollo socioeconómico. Es en estas áreas donde se localizan las nuevas inversiones. Es en las ciudades donde se concentran los servicios, donde se genera mayor cantidad de puestos de trabajo. También, en consecuencia, es en las ciudades donde deberemos enfrentarnos con problemáticas sociales y ambientales más complejas (MACRI ET AL., 2009, p. 7).

Por otro lado, existe un reconocimiento a una tendencia global en asumir posiciones semejantes en torno a problemas globales, que está cifrada en un registro comunitario: 
compartir, aprender, y no en términos de dependencia, industrias, división del trabajo internacional. Las ciudades compiten entre sí como mercancías que cotizan en el mercado, y lo harán de acuerdo con ventajas comparativas que presenten respecto de otras (PorTer, 1990).

También nos resulta inspirador advertir que no somos la única ciudad del mundo que ha iniciado este camino. Que no tenemos originalidad sino compañía, que no nos destacamos por ser diferentes en nuestros deseos, sino que estamos en condiciones de compartirlos y aprender de las buenas prácticas junto a otros ciudadanos del mundo. Porque los temas del futuro son temas comunes para todos, en especial, los que hacen a las cuestiones ambientales. Ninguna persona es ajena a esto, y en diferentes medidas, las responsabilidades son compartidas (MACRI ET AL., 2009, p. 7).

Dicha responsabilidad apunta a ejercer, a nivel individual, el peso de asegurar el propio bienestar: a escala colectiva, no imponer dicho peso como una carga social. Esto se deriva de una perspectiva de "buenas prácticas", es decir, de recuperación de aspectos o actitudes propios de otras experiencias (esto tiene lugar, primero, como estrategia de marketing entre empresas y, luego, entre gobiernos) cuyas derivaciones supongan un mejor y más eficiente uso de recursos públicos: esto se corresponde con el marco establecido anteriormente por BRown (2015). Luego, la ciudad es concebida en su posición a nivel nacional y en su dimensión metropolitana:

En este Modelo Territorial pensamos la Ciudad para el servicio nacional y consideramos además que esta es parte e impulso de todo el desarrollo metropolitano. Nuestra visión se relaciona con otro gran desafío de las ciudades de hoy, que es lograr la sustentabilidad en términos de equidad. Las acciones que nos proponemos y pensamos orientar con este Modelo se encaminan no solo a lograr el crecimiento (sabemos que esto únicamente no basta), sino a lograr el desarrollo humano equilibrado (MacRi et AL., 2009, p. 7).

Dicho desarrollo humano consiste en el despliegue estatal de los medios y mecanismos propicios para que el ciudadano-emprendedor tome las riendas de su propio bienestar: la intervención política planteada asume tal direccionalidad. La sustentabilidad como tal pareciera solo alcanzable mediante este papel activo del Estado que planifica y dispone las condiciones para alcanzarla a partir de relaciones socioeconómicas y socioambientales más "eficaces", articuladas por expectativas, valoraciones y métricas propias de un comportamiento consistente con las del homo economicus neoliberal (Brown, 2015): 
El objetivo de alcanzar este desarrollo humano no se logra sin planificación, sin visión de largo plazo y sin voluntad de acción. Creemos estar en el camino adecuado, y que este Modelo Territorial nos ayudará a dirigir nuestros pasos de forma más segura y eficaz (MACRI ET AL., 2009, p. 7).

A continuación, transcribimos una de las escasas definiciones técnicas concretas que el texto reseña para justificar la fuente de sus perspectivas y criterios teórico-metodológicos, y se evidencia la relación entre el plano de la planificación local con organismos internacionales:

Entre estas, cabe destacar el Grupo Intergubernamental de Expertos sobre el Cambio Climático (IPCC, International Panel on Climate Change), el Programa de las Naciones Unidas para el Medio Ambiente (PNUMA), la red de Mercociudades; incluso, la participación más reciente en la Cumbre Mundial de Grandes Ciudades-C40, grupo que se constituyó con alrededor de sesenta ciudades y grandes ciudades de todo el mundo, comprometidas con la tarea de revertir el cambio climático. Este Modelo Territorial funciona como estructura teórica y marco de intervención para implementar varias de las acciones que se plantean y acuerdan en este nivel regional y global (MACRI ET AL., 2009, p. 7).

Pasaremos ahora a analizar el discurso de CHAín, el cual caracterizamos conceptualmente como "especificidad histórica del MT: vector de la planificación, en términos de sustentabilidad”. Aquí se pone de manifiesto que las metodologías y los valores acerca de cómo concebir la ciudad en términos prospectivos y sobre cómo alcanzarlos son cualitativamente distintos de los que guiaban a los modelos previos. La asunción de la sustentabilidad como principio urbano se justifica una vez enmarcada en su especificidad histórica, y así, justifica la postura adoptada por quienes deciden plasmarla en este documento guía de la función pública presente y futura. Ante los desequilibrios sistémicos anticipables, se plantea que

Las ciudades en general, tienen hoy como principal desafío lograr la sustentabilidad, concepto que debe ser entendido en un sentido amplio y multivariable. Los diferentes tipos de desequilibrios son los que atentan contra la sustentabilidad. Hemos aprendido a la fuerza que no basta con tener crecimiento económico y un Estado que realice obras puntuales para mejorar los niveles de confort y habitabilidad existentes en la urbe. Si no se modifican los patrones de desequilibrio que se mantienen en el tiempo, alcanzar niveles de sustentabilidad mínimamente deseables se vuelve una tarea dificultosa, cuando no imposible o al menos, pueril (MACRI ET AL., 2009, p. 8). 
El documento plasma el rol gubernamental de descifrar los desafíos hacia la sustentabilidad: los indicadores presumen oficiar como guías orientativas acerca de esos desafíos y contribuyen a saber no solo dónde observar, sino qué hay que mejorar en cada oportunidad: "Confiamos en que la planificación es capaz de responder a los desafíos de la sustentabilidad urbana, siempre y cuando se oriente a identificar los puntos críticos, es decir, que logre descifrar las lógicas del desequilibrio actual” (MACRI ET AL., 2009, p. 8).

Se evidencia así la relación saber-poder: la ciencia sirviendo a una vocación de ejercicio del poder, brindando elementos para dotar de inteligibilidad a los problemas, rasgo que remite a la definición de gubernamentalidad vinculada con la de racionalidades políticas que consideramos. Los conceptos presentados de "ciudad deseada" y "ciudad proyectada" (que luego será nombrada como deseada), por ejemplo, son frutos de esta elaboración, gracias a una metodología para conocer la ciudad, evaluarla, diseccionarla:

Para las acciones de gobierno actuales y futuras ofrecemos, con este Modelo Territorial, más que un deseo y un proyecto: agregamos a los activos del Estado una metodología que permite realizar evaluaciones sobre la gestión. El conjunto de indicadores con los que se analiza y proyecta la Ciudad funciona como el tablero de comando que ya se está aplicando para medir la performance de las intervenciones físicas sobre el territorio (Macri et AL., 2009, p. 8).

En suma, esto evidencia una concepción organicista de la sociedad que se busca, por un lado, aprehender, y por otro, gobernar: del desentrañamiento de sus características, posible a través del despliegue de los indicadores, será posible conocer mejor, para gobernar con criterios de eficiencia. Dicha eficiencia, de acuerdo con este discurso, supone una relación de equilibrio, de balance, entre las variables económica, ambiental y social.

En cuanto al discurso de Lostri, que en esta oportunidad hemos categorizado como "la metodología y la asociación entre riesgo-velocidad en torno a la adaptación sistémica”, observamos que en el documento no se revela cómo se eligieron los indicadores ni el diseño metodológico detrás de los diagnósticos realizados. Tampoco se comentaron las discusiones detrás de su elección. Empero, estas tres introducciones se erigen como una suerte de manifiesto político "sustentable":

El Modelo Territorial permite dar a conocer la trastienda de estas transformaciones urbanas, es decir, muestra que aquellas transformaciones, que podrían parecer aisladas, son producto de 
estudios diagnósticos y proyecciones realizadas mediante una metodología rigurosa, basada en criterios e indicadores urbanos de un importante nivel de detalle. Este Modelo Territorial es entonces una publicación que expone, entre otros aspectos, todas las herramientas metodológicas que hacen al estudio de la Ciudad, pero desde una perspectiva política y estratégica, antes que tecnológica (MACRI ET AL., 2009, p. 9).

La urgencia de la planificación responde a la necesidad de inserción global eficiente, cuyo criterio máximo es sustentable. La insistencia con la celeridad del tiempo permite asentar las relaciones entre las variables claves para pensar en el contexto histórico en que se sitúan los planificadores: se monta así una asociación entre riesgo-velocidad y la proyección a futuro como ejercicio de adaptación. La metodología habilitaría, presuntamente, tal adaptación al futuro porque hace visible lo que "sucede" y permite entenderlo. Consiguientemente, puede transformar la situación y llevar los indicadores de valores de déficit a óptimos:

Buenos Aires se inserta en el concierto global en sus movimientos más rápidos, más vigorosos. Pensar la Ciudad futura es un riesgo y un desafío que supone considerar que, de aquí a unos pocos años, los conceptos de espacio y tiempo se definirán a partir de nuevas premisas. Proyectar a futuro la evolución tecnológica del último siglo se convierte en un ejercicio saludable, en una forma de adaptación necesaria al vértigo asociado a la velocidad de los cambios ocurridos, pero, más que nada, a la velocidad de los cambios por venir (MAcri eT AL., 2009, p. 9).

La capacidad anticipatoria de este proyecto considera que existen escenarios futuros que responderán a características y necesidades diferentes de las actuales. Correspondiendo a esta perspectiva, se afirma que el documento trascenderá los gobiernos presentes, y por eso, el propio MT presenta la característica clave de "adaptarse", de ser flexible:

Pensar nuevas autopistas para un tiempo venidero en el que, quizá, la mayoría de la población de las grandes megalópolis no necesite abandonar su hogar para realizar un trabajo, puede resultar paradójico o incluso, inútil. Por eso, más allá de las propuestas específicas que se han desarrollado considerando las tendencias existentes, el Modelo Territorial fue pensado como instrumento flexible, como herramienta de control de alternativas, como metodología transformadora y adaptable a los cambios por venir (MACRI ET AL., 2009, p. 9). 


\section{Palabras finales}

En suma, observamos que la racionalidad política expresa cierta opacidad respecto del proceso de construcción de los indicadores, reservado solo a los planificadores que elaboraron el MT. A partir de esta metodología se plantea la vocación de asemejar la ciudad a una noción particular de sustentabilidad. Dicha correspondencia entre ciudad sustentable deseada sería el resultado de una secuenciación de ciudades: escalones de un recorrido progresivo que ata al MT con el ejercicio del poder de gobierno de la gestión responsable de su publicación, y con las sucesivas administraciones.

La presunta eficacia de la incorporación de la sustentabilidad en el gobierno de las dimensiones económica y ambiental se presenta, asimismo, como un factor clave para que la ciudad, como sistema, resista a posibles escenarios de crisis. Podría decirse, por ende, que se trata de una acepción conservadora de la noción de sustentabilidad, en la que la dimensión social queda subordinada a las dos antes mencionadas: los contextos de marginalidad y vulnerabilidad emplazados en áreas de la ciudad son abordados solo en tanto la preocupación ambiental los revela como problemáticos. De no ser así, en los discursos de los tres exfuncionarios no se vislumbra el contexto social del surgimiento y de la importancia en sí misma de la pobreza.

Asimismo, destacamos el establecimiento de la "humanización del espacio público" como prioridad, rasgo vinculado con la antropología subyacente al humano que servirá de molde para la ciudad. En pleno desplazamiento del eje de lo social a lo ecológico, la eficaz y sinérgica articulación de cadenas de valor y la diversificación de las industrias de la ciudad hacen a la resiliencia sistémica de una ciudad que apunta a su capitalización como horizonte deseado. Semejante desplazamiento se da a partir de la vocación de apuntalar la configuración de la subjetividad de la población conforme a este sujeto que admite una disposición sacrificial respecto de su participación en la esfera pública y en cuanto al goce de derechos y libertades. Si el espacio público es constituido con base en esta figura, cuya humanidad está íntimamente vinculada con la de capital humano, lo que se rescata es la vocación, por parte de las autoridades políticas de abonar a una transferencia de valor de la población respecto de la ciudad: su competitividad económica y su fortaleza para enfrentar crisis.

La humanización del espacio público no significa, en estos términos, un ensanchamiento del espacio de aparición del público, sino la intensificación de las características de la 
ciudad más vinculadas con el dinamismo de las industrias de la ciudad; en otras palabras, con las condiciones de acceso al mercado de trabajo y a la inversión privada, en la que el homo economicus actúa como un actor que pondera su encumbramiento como emprendedor antes que como ciudadano. Por todo esto, sostenemos, la acepción del concepto de sustentabilidad observado en el análisis de enunciados como los relevados a partir del MT sugiere la explicitación de un papel activo del Estado en la planificación de los medios para realizar semejante humanización que cambia de modo sustantivo las capacidades y usos del espacio público de la ciudad. Dicha humanización responde al paradigma de la sustentabilidad en su acepción más eminentemente neoliberal: propugna la promoción de modos de habitar, circular y producir en la ciudad que presenten una presunta armonía, susceptible de ser cuantificada y, por tanto, gobernada.

Si el MT puede aprehenderse como documento de planeamiento y, a su vez, en su textualidad, como expresión de las autoridades oficiales de su vocación de ejercer el poder político, el modelo del homo economicus del neoliberalismo ofrece un tipo de subjetividad acorde. Precisamente, la humanización del espacio entendida como articulación eficaz entre dimensiones económica, ambiental y social supone la primacía de la competitividad y la integración de capacidades entre sus habitantes, entendidos principalmente como actores económicos antes que políticos: el gobierno de la población se concibe, pues, en los términos de la gubernamentalidad neoliberal, en un modo histórica y explícitamente original para la ciudad.

\section{Referencias bibliográficas}

ARENDT, H. (2014 [1958]). La condición humana. Buenos Aires: Paidós.

BABB, S. (2005). The Social Consequences of Structural Adjustment: Recent Evidence and Current Debates. Annual Review of Sociology. Vol. 31, pp. 199-222.

BETTENCOURT, L. M. A. \& KAUR, J. (2011). The evolution and structure of sustainability science. Proceedings of the National Academy of Sciences, United States. Vol. 108, pp. 19540-19545.

BROCKLING, U. (2011). Human Economy, Human Capital: A Critique of Biopolitical Economy en Bröckling, U., Krasmann, S. \& Lemke, T. eds., Governmentality Current Issues and Future Challenges, pp. 247-269. NYC: Routledge.

BROWN, W. (2015). Undoing the demos: neoliberalism `s stealth revolution. NYC: Zone Books. 
CENTNER, R. (2009). Conflictive sustainability landscapes: the neoliberal quagmire of urban environmental planning in Buenos Aires. Local Environment, Vol. 14, No. 2, pp. 173-192

ESPINA, H. A.; FORAY, F.; LERENA RONGVAUX, N. \& MORONI, M. M. (2013) Planeamiento Estratégico en la Ciudad de Buenos Aires: ¿qué ciudad desea el Modelo Territorial?Ponenciapresentada enEJEd) GeografíaUrbanaXIVEGAL, Lima, Perú. Recuperado de: http://www.observatoriogeograficoamericalatina. org.mx/egal14/Geografiasocioeconomica/Ordenamientoterritorial/31.pd

DILTS, A. (2011). From 'Entrepreneur of the Self' to 'Care of the Self': Neo-liberal Governmentality and Foucault's Ethics. Foucault Studies, 12, 130-146.

FOUCAULT, M. (1991). Governmentality. En Burchell, Graham, Colin Gordon and Peter Miller, The Foucault Effect: Studies in Governmentality. Chicago: University of Chicago Press, pp. 87-104.

FOUCAULT, M. (2012). Nacimiento de la biopolítica. Bs.As.: FCE. Trad.: Horacio Pons.

GIBSON, R. B. (2006). Sustainability assessment: basic components of a practical approach. Impact Assessment and Project Appraisal, 24: 3, pp. 170-182.

GORDON, C. (1991). Governmental Rationality: An Introduction. En The Foucault Effect: Studies in Governmentality. Editado por Burchell, Graham, Colin Gordon and Peter Miller, 1-51. Chicago: University of Chicago Press.

HSIEH, H-F. \& SHANNON, S. E. (2005). Three Approaches to Qualitative Content Analy-sis. Qualitative Health Research, Vol. 15, No. 9, November 2005: 1277-1288.

JAJAMOVICH, G. (2012). Apuntes para una crítica al Modelo Territorial de Buenos Aires: Lo que plantea y lo que excluye. Café de las Ciudades, 11, 118. Recuperado de: https://cafedelasciudades.com.ar/planes_118.htm

LEACH, Melissa; SCOONES, Ian \& STIRLING, Andy (2010). Dynamic Sustainabilities: Technology, Environment, Social Justice. Earthscan, UK.

LEMKE, Thomas (2001). The Birth of Bio-Politics - Michel Foucault’s Lecture at the Collège de France on Neo-Liberal Governmentality. Economy \& Society, Vol. 30. No. 2, 190-207.

LEMKE, T. (2002). Foucault, Governmentality, and Critique. Rethinking Marxism, 14 (3), 49-64. 
LEMKE, T. (2007). An Indigestible Meal?: Foucault, Governmentality and State Theory, Distinktion: Scandinavian Journal of Social Theory 8.2 (2007), pp. 43-64.

MACRI, Mauricio; CHAIN, Daniel; LOSTRI, Héctor (2009). Modelo Territorial Buenos Aires 2010-2060 / edición literaria a cargo de Mauricio Macri; Daniel Chain; Héctor Lostri. Primera ed. Buenos Aires: Ministerio de Desarrollo Urbano del Gobierno de la Ciudad Autónoma de Buenos Aires. Recuperado de https://www.mininterior.gov.ar/planificacion/pdf/planes-loc/CABA/ Modelo-territorial-2010-2060.pdf

NEUENDORF, K. A. (2002). The content analysis guidebook. London: Sage Publications.

MOHAN, Giles; BROWN, Ed; MILWARD, Bob \& ZACK-WILLIAMS, Alfred B. (2000). Structural adjustment: theory, practice, and impacts. London, primera edición.

ROSE, N. \& MILLER, P. (1992). "Political Power beyond the State: Problematics of Government” en The British Journal of Sociology, Vol. 43, No. 2, pp. 173-205.

PORTER, M. (1990). The Competitive Advantages of Nations. NY: Free Press.

REDMAN, C. L. (2014). Should sustainability and resilience be combined or remain distinct pursuits? Ecology and Society, Vol. 19, pp. 2-37.

RIECHMANN, J. (1995). Desarrollo sostenible: la lucha por la interpretación. En Jorge Riechmann y otros (compiladores), De la economía a la ecología. Madrid: Trotta.

RIECHMANN, J. (2003). Tres principios básicos de justicia ambiental. RIFP/21 (2003), pp. 103-120.

RIECHMANN, J. (2005). ¿Cómo cambiar hacia sociedades sostenibles? Isegoría, No. 32 (2005), pp. 96-117.

SMITH, A. \& STIRLING, A. (2010). The politics of social-ecological resilience and sustainable socio-technical transitions. Ecology and Society, Vol. 15(1): 11.

THEODORE, N., PECK, J. \& BRENNER, N. (2009). Urbanismo neoliberal: la ciudad y el imperio de los mercados. Temas Sociales, 66, 1-11.

VELTMEYER, Henry; PETRAS, James \& VIEUX, Steve (1997). Capítulos I, II y III. En Neoliberalism and class conflict in Latin America: a comparative perspective on the political economy of structural adjustment. New York, NY: Palgrave Macmillan, pp. 1-92. 


\section{Normas de publicación}

CUADERNO URBANO es una publicación científica con arbitraje internacional dirigida a la difusión de artículos y ensayos que se ocupan de la cuestión urbana —en el sentido más amplio del término - desde las disciplinas científicas, combinando trabajos de caracteres empíricos, teóricos y ensayísticos que den cuenta de problemáticas locales, regionales y universales. La intención de la publicación es favorecer y promover la generación de ensayos y artículos de jóvenes investigadores con las reglas de arbitraje científico, colaborando en la producción editorial de sus ideas, como también divulgar el aporte de científicos ya consagrados en su especialidad disciplinar, a través de una sección especial de fondo.

\section{Instrucciones para los autores}

\section{Alcance y política editorial}

La dirección editorial recibirá contribuciones originales y las considerará en dos instancias. En la primera analizará los aspectos formales especificados más abajo con respecto a la extensión del artículo, la tipografía, el cuerpo, el interlineado, la bibliografía etcétera, mientras que en la segunda considerará la pertinencia del contenido, la estructura y su claridad expositiva. En esta instancia, la dirección editorial podrá aceptar, rechazar o sugerir cambios sobre el artículo puesto a consideración. En este último caso, de mediar acuerdo con el autor, este deberá realizar las enmiendas necesarias y reenviar el artículo al Comité Editorial para su reconsideración.

Una vez aceptados los trabajos, serán enviados a dos evaluadores del Comité Arbitral de la publicación o a dos seleccionados entre académicos de reconocida capacidad en el tema que trata el artículo y a un tercero, que dirimirá si existen opiniones opuestas entre ambos. Recibidas las evaluaciones, el Comité Editorial hará saber al autor los resultados mediante un dictamen unificado, guardando las reservas adecuadas. Las evaluaciones se harán por pares ciegos (autores y evaluadores se mantienen anónimos entre sí). Una vez aceptado el artículo, la fecha de su publicación queda a criterio de los directores editoriales en función del orden de recepción y la pertinencia del tema en el contexto general de la publicación de cada número. En todos los casos, la dirección editorial comunicará al autor el número de la publicación en el que saldrá su contribución. 
Los trabajos deberán ser inéditos y, una vez enviados, los autores se comprometerán a no presentarlos en otra publicación. No se publicará más de un trabajo por autor, ya sea individual o en coautoría. Los autores aceptarán los cambios de estilo que sean necesarios para una mejor comprensión de los artículos. Estas correcciones no alterarán su contenido. Los autores serán responsables del contenido de sus contribuciones. El origen de las figuras, cuadros, gráficos, etcétera, deberá aparecer en el manuscrito, ya sea en forma de leyenda o como agradecimientos.

\section{Tipos de trabajos}

Cuaderno Urbano publica los siguientes tipos de contribuciones:

1. ARTÍ́CULOS ARBITRADOS. Resultados de investigación terminados, originales e inéditos, que de manera metódica constituyan un aporte al ámbito temático de Cuaderno Urbano, o bien que estén construidos a partir de la experiencia de trabajo en el área, desde una perspectiva crítica y analítica. Dentro de esta sección, se aceptan estudios de caso que aporten datos y metodologías cuyo valor radique en la posibilidad de establecer comparaciones, reflexiones o hipótesis de un mayor nivel de generalidad, que trasciendan el interés local del caso tratado. Las contribuciones científicas que llegan a esta sección pasan por el doble proceso de evaluación que se describe en el apartado anterior y deben ajustarse a la normas de presentación. Pueden tener una extensión de entre 4000 y 7500 palabras. Cada número de la revista incluye entre cinco y seis artículos arbitrados, de acuerdo con su extensión.

2. REPORTAJE DE CIUDADES. Artículo destinado a presentar rasgos o características de una ciudad en particular o un conjunto de ciudades que comparten rasgos comunes, desde algún tópico de interés dentro de la temática de la revista, o bien algún fenómeno urbano relevante que se esté produciendo en ella o ellas. Por su carácter, esta sección admite una extensión más corta (entre 4000 y 6000 palabras), y se exige mayor número de imágenes (hasta veinte). Las contribuciones a esta sección pasan por la evaluación exclusiva del Comité Editor, y en muchos casos se trata de contribuciones hechas por invitación o a pedido de este.

3. ARTÍCULOS DE FONDO. Destinados a difundir contribuciones de investigadores o académicos de dilatada trayectoria. Los trabajos suponen una aportación conceptual significativa al debate disciplinar, y pueden ser resultado de investigaciones específicas o bien tener el carácter de ensayos o de artículos de opinión sólidamente fundamentados. 
4. RESEÑA BIBLIOGRÁFICA. Esta sección incluye contribuciones breves de hasta 2500 palabras que den a conocer libros editados por universidades o centros de investigación de reciente aparición sobre la temática de Cuaderno Urbano. Las reseñas deben incluir la cita bibliográfica completa del libro (título, autor/es, editorial, lugar y fecha), una síntesis descriptiva del libro, comentarios sobre las contribuciones que hace a la temática que aborda y alguna valoración final que destaque el interés que puede tener para los lectores de Cuaderno Urbano.

\section{Forma y preparación de manuscritos}

1. Los trabajos enviados para la sección de artículos arbitrados tendrán una extensión total de entre 4000 y 7500 palabras, e incluirán obligatoriamente los siguientes ítems: título, nombre del/los autor/es, breves antecedentes y pertenencia institucional; resumen (en español e inglés, no mayor de 150 palabras cada uno); de tres a cinco palabras clave (también en ambos idiomas); el texto del artículo y la bibliografía citada. Dentro de esta extensión también podrán incluirse, si se considera necesario, notas de referencias, tablas, cuadros, ilustraciones, imágenes y agradecimientos.

2. La primera página contendrá título del artículo, nombre/s del/los autor/es, breves antecedentes y pertenencia institucional. La segunda página contendrá el título del artículo, los resúmenes en español e inglés y un máximo de cinco palabras en ambos idiomas. Desde esta página al final no deberá figurar el nombre del o los autores y ningún tipo de encabezado, solamente el número de página en la parte inferior a la derecha.

3. EL TEXTO: debe ser de cuerpo 10, tipo Arial, interlineado 1,5 y alineación justificada, sin corte de palabras. Todos los subtítulos primarios deben tipearse sin tabulado en mayúscula, sin subrayar y en negrita, sobre el margen izquierdo, a dos espacios del texto que los precede y a uno del que lo sigue. Los subtítulos secundarios deben tipearse sin tabulado en minúscula y en negrita sobre el margen izquierdo, a dos espacios del texto que los precede y a uno del que lo sigue. En caso de precisar numerar los títulos y subtítulos, se utilizará numeración latina (1,1.1., etc.). Los párrafos comenzarán sin tabulado ni sangría, y se dejará un interlineado libre entre ellos. Todo lo que el autor desea destacar, esto es, palabras o expresiones en otro idioma no incorporadas al uso habitual de la lengua española (incluyendo los nombres científicos de animales y vegetales), se escribirá en cursiva o bastardilla. 
4. LAS ILUSTRACIONES: los cuadros, tablas, diagramas y gráficos (con su respectiva numeración, escalas, títulos o epígrafes) se deben entregar en archivos independientes, en programas Word o Excel, en tipografía Arial, cuerpo 9, sin sobrepasar un ancho de caja de $15 \mathrm{~cm}$. Las imágenes de fotografías o mapas también se deben entregar en archivos independientes en formato JPG. Estas tienen que ser preferentemente en blanco y negro, con una definición de 300 dpi o píxeles por pulgada. Su dimensión no debe ser menor de 15 $\mathrm{cm}$ de lado. Se debe tener en cuenta la legibilidad de la información dentro de estos tamaños. En el texto del trabajo se deberá indicar la ubicación de cada una de las ilustraciones mediante una referencia que diga figura 1, 2, 3, etc., que se ubicará en el lugar que se desea que sea insertada la ilustración correspondiente, dejando un interlineado libre antes y después de ella. En caso de archivos de imágenes (JPG), los epígrafes serán colocados en el texto debajo de la referencia correspondiente. En todos los casos se debe mencionar la fuente de la información.

5. LAS NOTAS: deberán estar numeradas correlativamente, en numeración latina, y colocadas al final del texto (no se aceptarán notas a pie de página). Las notas no tienen que permitir hacer referencia sobre quién/es es/son el/los autor/es del artículo.

6. LISTA DE REFERENCIAS Y CITACIÓN: los trabajos se adecuarán a las normas APA, cuyas consideraciones principales proporcionamos en este resumen, adaptado de $\mathrm{Manual} \mathrm{de} \mathrm{Pu}$ blicaciones de la American Psychological Association, 2010 (traducida por Miroslava Guerra Frías). Editorial El Manual Moderno, México, 278 pp. Tercera edición traducida de la sexta en inglés.

\section{Citación de fuentes}

A modo de paráfrasis, con citas directas de un autor o al describir una idea, teoría o investigación de alguna persona, siempre se debe dar cuenta de la fuente, de manera de evitar el plagio e incluso el autoplagio.

Se debe reproducir al pie de la letra el material citado directamente del trabajo de otro autor o de su propio trabajo previamente publicado y el material duplicado de un artículo de prueba. Siempre hay que indicar el autor, año y la página específica de la cita. En caso de material no numerado, anotar el número del párrafo. 
Cuando las citas comprendan menos de 40 palabras, se incorporan en el texto entre comillas (anotar inmediatamente la fuente entre paréntesis).

Si comprenden 40 o más palabras, se despliegan en un bloque independiente del texto y se omiten las comillas, con un margen izquierdo de $2.54 \mathrm{~cm}$. Al final del bloque de citas, citar la fuente de consulta y el número de página o párrafo en un paréntesis después del signo de puntuación final.

Se deben acreditar las citas directas de material en línea indicando el autor, año y número de página entre paréntesis. En caso de que la publicación no presente número de página, explicitar el número de párrafo, con la abreviación párr.

Las citas directas deben ser precisas y seguir las palabras, la ortografía y la puntuación de la fuente original, incluso si presenta incorrecciones. En este caso, se inserta [sic], en cursivas y entre corchetes, para indicar que así figura en el original.

\section{Cambios en la fuente original}

La primera letra de la primera palabra citada puede cambiarse a mayúscula o minúscula. El signo de puntuación que finaliza la oración puede modificarse para adecuar la sintaxis. Las comillas sencillas pueden cambiarse por comillas dobles y viceversa. Cualquier otra modificación (como poner palabras en cursivas para enfatizar u omitir palabras) debe indicarse de manera explícita.

Si se quiere omitir material incluido en la fuente original, usar puntos suspensivos (...) en una oración para indicarlo. No usar puntos suspensivos al principio ni al final de cualquier cita. Usar corchetes para encerrar el material adicional o las explicaciones insertadas en una cita por una persona que no es su autor original. Si se quiere enfatizar una palabra o palabras en una cita, escribirlas en cursivas. Inmediatamente después de las palabras en cursivas, insertar entre corchetes cursivas añadidas ([cursivas añadidas]).

\section{Citación de referencias}

Las referencias en las publicaciones de la APA se citan en el texto con un sistema de citas de autor-fecha y se enlistan alfabéticamente en la lista de referencias. Cada referencia citada en el texto debe aparecer en la lista de referencia, y cada entrada de esta debe citarse en el texto. 


\section{Lista de referencias}

Presentamos ejemplos básicos de la forma de notación de las referencias bibliográficas.

\section{Publicaciones periódicas}

Autor, A., Autor, B. y Autor, C. (año). Título del artículo. Título de la publicación, volumen (número), pp. xx - pp. xx. doi: $\mathrm{xx} \cdot \mathrm{xxxxxxxxxx}$

Si el contenido no tiene DOI asignado y se recuperó en línea, incluir en la referencia la URL de la publicación con este formato: Recuperado de http://www.xxxxxxxx

\section{Artículo de periódico}

Autor (día del mes del año). Título del artículo. Nombre del periódico, pp. xx, xx.

Artículo de periódico en línea: igual al anterior, pero se le agrega Recuperado de http:// www.xxxxxxxx

\section{Libro completo}

Autor, A. A. (1967). Título del trabajo. Lugar: Editorial.

Autor, A. A. (1997). Título del trabajo. Recuperado de http://www.xxxxxxx

Autor, A. A. (2006). Título del trabajo. doi: $\mathrm{xxxxx}$

Editor, A. A. (Ed.). (1986). Título del trabajo. Lugar: Editorial.

\section{Capítulo de un libro o entrada de un libro de consulta}

Autor, A. y Autor, B. (1995). Título del capítulo o entrada. En A. Editor, B. Editor y C. Editor (Eds.), Título del libro (pp. xxx-xxx). Lugar: Editorial.

En línea, se agrega Recuperado de http://www.xxxxxxx y si tiene DOI se lo especifica.

\section{Actas de congresos y simposios}

Para actas que se publican habitualmente, emplear el mismo formato de una publicación periódica. 


\section{Informes técnicos y de investigación}

Autor, A. (1998). Título del trabajo (Informe No. xxx). Lugar: Editorial.

\section{Disertaciones doctorales y tesis de maestría}

Autor, A. (2003). Título de la tesis doctoral o de maestría (Tesis doctoral o tesis de maestría). Recuperada de Nombre de la base de datos. (Acceso o Solicitud No.)

Si fuera inédita, consignarlo en la aclaración.

\section{Trabajos inéditos o de publicación informal}

Autor, A. A. (Año). Título del manuscrito. Manuscrito inédito [o "Manuscrito presentado para su publicación” o "Manuscrito en preparación”].

Envío de artículos

Normas para la presentación de artículos

Los trabajos, realizados en Microsoft Word, deberán ser enviados por correo electrónico a cuadernourbano@gmail.com y mabarreto@arnet.com.ar.

Si se prefiere, podrán remitirse por correo postal a la siguiente dirección:

\section{CUADERNO URBANO}

Facultad de Arquitectura, Universidad Nacional del Nordeste

Av. Las Heras 727 (Pabellón Arquitectura)

H3500 Resistencia, Chaco, Argentina

En este caso deben enviarse una copia impresa en papel y una versión digital en CD ROM. 